\title{
On the Survival of Peptide Cations After Electron Capture: Role of Internal Hydrogen Bonding and Microsolvation
}

\author{
Tapas Chakraborty \\ Department of Chemistry, Indian Institute of Technology, Kanpur, India
}

\author{
Anne I. S. Holm, Preben Hvelplund, Steen Brøndsted Nielsen, \\ Jean-Christophe Poully, and Esben S. Worm \\ Department of Physics and Astronomy, University of Aarhus, Aarhus, Demark
}

Evan R. Williams

Department of Chemistry, University of California at Berkeley, Berkeley, California, USA

\begin{abstract}
Electron capture by both bare and microsolvated small peptide dications was investigated by colliding these ions with sodium vapor in an accelerator mass spectrometer to provide insight into processes that occur on the microsecond time frame. Survival of the intact peptide monocation after electron capture depends strongly on molecular size. For dipeptides, no intact reduced species were observed; the predominant ions correspond to loss of hydrogen and ammonia. In contrast, the intact reduced species was observed for larger peptides. Calculated structures indicate that the diprotonated dipeptide ions form largely extended structures with low probability of internal ionic hydrogen bonding (i.e., charge solvation) whereas internal ionic H-bonding occurs extensively for larger peptide dications. Solvation of the peptide ions with between one to seven methanol molecules reduces the total extent of $\mathrm{H}$ loss even for dipeptides where intact reduced species can survive more than a microsecond after electron capture. The yield of ions corresponding to cleavage of $\mathrm{N}-\mathrm{C}_{\alpha}$ bonds $\left(c^{+}\right.$and $z^{+}$ ions) does not depend strongly on peptide size but decreases with the extent of microsolvation for the dipeptide dications. H-bonding appears to play an important role for the survival of the intact reduced ions but less so for the formation of $c^{+}$and $z^{+\cdot}$ ions. Our results indicate that electron capture predominantly occurs at the ammonium groups (at least 70 to $80 \%$ ), and provides important new insights into the electron capture dissociation process. (J Am Soc Mass Spectrom 2006, 17, 1675-1680) (C) 2006 American Society for Mass Spectrometry
\end{abstract}

$\mathrm{E}$ lectron capture (EC) by peptide or protein cations in the gas phase can result in extensive backbone fragmentation from which information about the sequence as well as locations and identities of posttranslational modifications can be obtained [1-4]. EC can occur via interactions with thermally generated free electrons [1], collisions with anions [2], or with atoms [3]. These methods produce comparable fragmentation and are rapidly becoming important for the top-down approach to determine protein structure [4].

Several models have been proposed to explain the sequence-specific $c^{+}$and $z^{+\cdot}$ ions $[1,5]$. Although details of these mechanisms differ, there is a consensus on the importance of binding an $\mathrm{H}$ atom to the oxygen of the amide group thereby weakening the $\mathrm{N}-\mathrm{C}_{\alpha}$ bond. Still,

Published online August 22, 2006

Address reprint requests to Dr. S. Brøndsted Nielsen, Department of Physics and Astronomy, University of Aarhus, DK-8000 Aarhus C, Denmark. E-mail: sbn@phys.au.dk the prior history of the $\mathrm{H}$ is unknown: Does $\mathrm{C}=\mathrm{O}$ capture an $\mathrm{H}$ atom that is released after electron capture to ammonium? How important is internal H-bonding between an ammonium and an amide? Or does capture of the electron occur at the amide $\mathrm{C}=\mathrm{O}$ followed by fast proton abstraction from a nearby ammonium driven by the Coulomb attraction, as recently suggested by Syrstad and Tureček [5a]?

Previous results from our group have shown that the fragment ions of substance P (SP) formed by electron capture induced dissociation (ECID) are the same as those observed after capture of a free electron [3]. In ECID, the electron is transferred from a gas target, e.g., sodium vapor, to ions traveling with large velocities, the interaction time being a few femtoseconds. The dissociation timescale, corresponding to the flight time from the collision cell to the analyzer, is a few $\mu \mathrm{s}$, whereas the timescale for Fourier-transform ion cyclotron resonance mass spectrometry experiments that use free electrons is several ms to s. The ECID method 

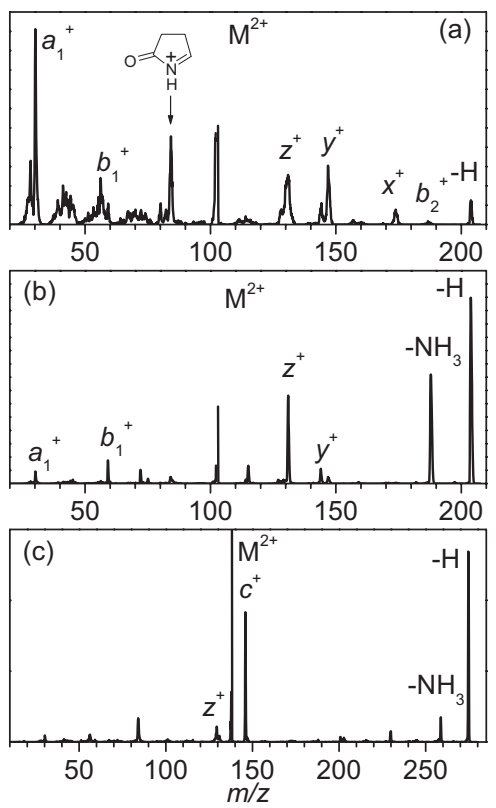

Figure 1. Product ion spectra obtained from the collisions between $[\mathrm{GK}+2 \mathrm{H}]^{2+}\left(=\mathrm{M}^{2+}\right)$ and $(\mathbf{a}) \mathrm{Ne}$ and $(\mathbf{b}) \mathrm{Na}$, and between $[\mathrm{KK}+2 \mathrm{H}]^{2+}$ and $\mathrm{Na}(\mathrm{c})$. The group of peaks from $\mathrm{m} / \mathrm{z} 30$ to 74 seen most clearly in panel (a) is assigned to different cleavages of the lysine side-chain, as a result of collisional activation. The ion corresponding to the $m / z-84$ peak is assigned according to $[7,8]$.

makes it possible to study early events in the dissociation process that cannot readily be observed using other methods.

In this work, we report ECID spectra of small protonated peptides and their microsolvated clusters and show that the survival of charge-reduced ions on a $\mu \mathrm{s}$ timescale strongly depends on intra- and intermolecular H-bonding interactions. Our data also indicate that internal ionic $\mathrm{H}$-bonding to the amide is not necessary for the $\mathrm{N}-\mathrm{C}_{\alpha}$ bond cleavage to occur. This study of small peptides, in some of which the Coulomb repulsion dictates a high propensity for an extended structure, provides new insights into some of the questions regarding the mechanism of ECD.

\section{Experimental}

Doubly-protonated peptides were generated by electrospray $(50 / 50 \%$ water/methanol with $1 \%$ acetic acid), introduced into an accelerator mass spectrometer [6], accelerated to $100 \mathrm{keV}, \mathrm{m} / \mathrm{z}$ selected, and passed through a heated $\left(220^{\circ} \mathrm{C}\right) \mathrm{Na}$ vapor cell. During the few fs interaction time of the collision, electron transfer of the $3 \mathrm{~s}$ electron of $\mathrm{Na}$ to a peptide ion can occur. Fragment ions were analyzed by a hemispherical electrostatic analyzer [6]. In addition to electron capture, ion activation occurred for collisions with low impact parameters, and fragments produced via this channel were measured in separate experiments in collisions with $\mathrm{Ne}$, also under single-collision conditions. Proper subtraction of the $\mathrm{Ne}$ and $\mathrm{Na}$ spectra reveals fragments produced predominantly from electron capture.

\section{Results and Discussions}

ECID spectra of $[\mathrm{GK}+2 \mathrm{H}]^{2+}$ and $[\mathrm{KK}+2 \mathrm{H}]^{2+}$ are presented in Figure 1 together with the Ne spectrum of $[\mathrm{GK}+2 \mathrm{H}]^{2+}$. In the latter, the dominant ions are $a^{+}$and $y^{+}$types whereas $c^{+}$and $z^{+\cdot}$ ions dominate in the $\mathrm{Na}$ spectra together with ions formed by loss of $\mathrm{H}$ or $\mathrm{NH}_{3}$. Interestingly, the $z^{+\cdot}$ ion dominates over the $c^{+}$ion for GK whereas the opposite is the case for KK. The different abundances may be due to the lability of the $z^{+\cdot}$ radical cations, but no evidence for significant secondary dissociation is observed. The physics of the capture process is governed by the electrostatic attraction between the charged ammonium group and the loosely bound $3 \mathrm{~s}$ electron of sodium, and it therefore seems unlikely that the capture probabilities of the two charged groups are significantly different. The fact that $c^{+}$and $z^{+\cdot}$ ions are formed with rather different probabilities suggests that capture to only one of the ammonium groups leads to $\mathrm{N}-\mathrm{C}_{\alpha}$ bond cleavage (likely in competition with $\mathrm{H}$ and $\mathrm{NH}_{3}$ loss) whereas capture to the other group solely causes $\mathrm{H}$ or $\mathrm{NH}_{3}$ losses. The peptide radical monocations, $[\mathrm{GK}+2 \mathrm{H}]^{+\cdot}$ and $[\mathrm{KK}+$ $2 \mathrm{H}]^{+}$, were not observed, indicating that the lifetimes of these species are sub $\mu \mathrm{s}$.

To shed more light on the hydrogen and ammonia loss process, we carried out experiments on partially deuterated peptides. Results for $[\mathrm{GK}+2 \mathrm{H}]^{2+}-d_{7}$ in which seven of the exchangeable hydrogen atoms were replaced by deuterium are shown in Figure 2. The exchangeable protons are the ammonium group protons, the carboxylic acid proton and the amide proton. From the peaks corresponding to ammonia loss, the two ammonium groups contain five $\mathrm{D}$ and one $\mathrm{H}$ since the two peaks corresponding to loss of $\mathrm{ND}_{3}$ and $\mathrm{ND}_{2} \mathrm{H}$ are roughly of the same intensity. The barrier for ammonia loss is low, about $9 \mathrm{~kJ} \mathrm{~mol}^{-1}(0.09 \mathrm{eV})$ for $\mathrm{H}_{3} \mathrm{~N}-\mathrm{GG}$, according to calculations by Tureček and Syrstad [9].

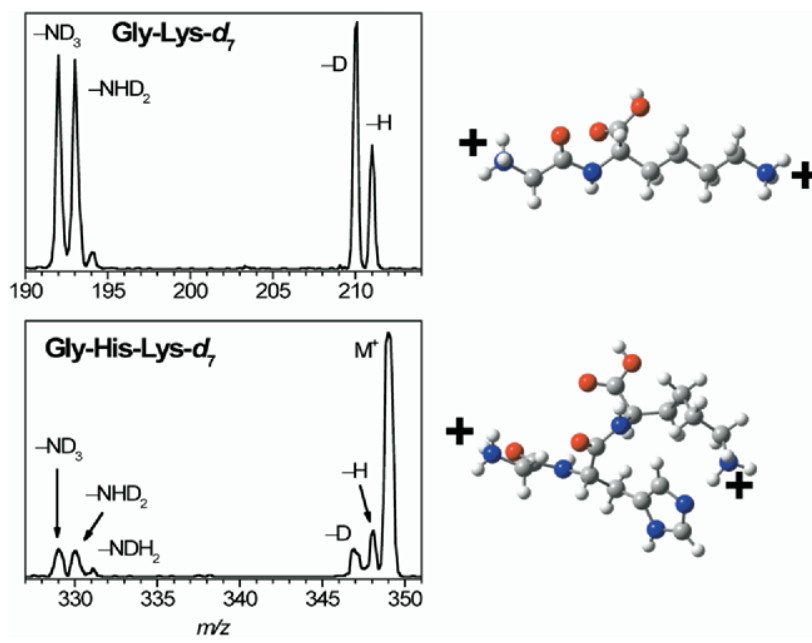

Figure 2. Partial ECID spectra of (a) $[\mathrm{GK}+2 \mathrm{H}]^{2+}-d_{7}\left(=\mathrm{M}^{2+}\right)$ and $\mathrm{Na}$ and $(\mathbf{b})[\mathrm{GHK}+2 \mathrm{H}]^{2+}-d_{7}\left(=\mathrm{M}^{2+}\right)$ and Na; PM3 optimized structures right. 
ECID results in loss of either $\mathrm{D}$ or $\mathrm{H}$ in a 2:1 ratio, significantly less than the statistical prediction of $5: 1$ (assuming that the two ammonium groups on average contain $5 \mathrm{D}$ and $1 \mathrm{H}$ and the other two deuteriums being present as $-\mathrm{COOD}$ and $-\mathrm{C}(\mathrm{O}) \mathrm{ND}-$ ). Similar results were obtained for AK and AR. There is more than one plausible explanation for the low ratio. First, there will be some contribution from the isobaric ion $[\mathrm{GK}+2 \mathrm{H}]^{2+}-d_{6}$ that contains one ${ }^{13} \mathrm{C}$ and some from $[\mathrm{GK}+2 \mathrm{H}]^{2+}-d_{6}$ due to the difficulty of isolating a single isotope with the magnet, but these "impurities" are not enough to explain such a low ratio. A barrier for hydrogen loss would disfavor $\mathrm{D}$ loss relative to $\mathrm{H}$ loss, i.e., a kinetic isotope effect. Such an interpretation is in agreement with previous observations: Williams and Porter found that the lifetime of the $\mathrm{NH}_{4}$ radical is shorter than that of $\mathrm{ND}_{4}$ and explained this by a higher zero point energy of $\mathrm{NH}_{4}$ relative to that of $\mathrm{ND}_{4}$ [10a]. Porter's group also found that $\mathrm{CH}_{3} \mathrm{ND}_{3}$ is more stable than $\mathrm{CH}_{3} \mathrm{NH}_{3}$ supporting a barrier to dissociation [10b]. Nguyen et al. [11] have reported an intramolecular isotope effect favoring cleavage of the $\mathrm{N}-\mathrm{H}$ bond in the $\left(\mathrm{CH}_{3}\right)_{2} \mathrm{NHD}$ radical. Based on calculations by Tureček and Syrstad [9], the barrier for $\mathrm{H}$ loss from the $\mathrm{H}_{3} \mathrm{~N}-\mathrm{GG}$ radical has been estimated to be low, $12 \mathrm{~kJ}$ $\mathrm{mol}^{-1}(0.12 \mathrm{eV})$, and the loss of hydrogen is itself only mildly exothermic, e.g., $28 \mathrm{~kJ} \mathrm{~mol}^{-1}(0.29 \mathrm{eV})$ in $\mathrm{H}_{3} \mathrm{~N}-\mathrm{GG}$ and $35 \mathrm{~kJ} \mathrm{~mol}^{-1}(0.36 \mathrm{eV})$ in $\mathrm{H}_{3} \mathrm{~N}$-lysine radicals. Loss of aliphatic $\mathrm{H}$ would also provide a lower ratio of $\mathrm{D}$ to $\mathrm{H}$ loss. However, according to work by Jeon et al. [10b] and Yao and Tureček [12], even though some loss of aliphatic $\mathrm{H}$ from hypervalent ammonium radicals such as methylammonium and ethylammonium has been observed, the loss of ammonium hydrogen usually dominates. Partial H/D scrambling of ammonium hydrogens and carbon hydrogens after electron capture but before $\mathrm{H}$ loss, via a free radical reaction cascade, would cause a lower ratio. Such a mechanism has been proposed by Leymarie et al. [13] to explain ECD of cyclic peptides where two bond breakages are needed, but is less likely to be important on the microsecond time scale of the present experiment. To summarize, deuterium labeling experiments confirm a sub $\mu$ s lifetime of dipeptide radical cations, but the actual reason for a small ratio of $\mathrm{D}$ to $\mathrm{H}$ loss is unclear.

In contrast to results for dipeptides, the chargereduced peptide radical cations of tripeptides survive (GGK was an exception). An example is shown for $[\mathrm{GHK}+2 \mathrm{H}]^{2+}-d_{7}$ in Figure $2 \mathrm{~b}$. The abundance of the intact radical cation is four times greater than that for the combined loss of $\mathrm{H}$ and $\mathrm{D}$. $\mathrm{H}$ is favored over $\mathrm{D}$ loss despite the $\mathrm{ND}_{2} \mathrm{H}$ and $\mathrm{ND}_{3}$ losses occurring with similar probabilities. Again, a kinetic isotope effect may play a role but the fact that the ratio between $\mathrm{D}$ and $\mathrm{H}$ loss has decreased compared with that of dipeptides indicates another source of the hydrogen than the ammonium group. Scrambling before hydrogen loss would decrease the ratio since the total number of hydrogen atoms in the tripeptide is larger than in the dipeptide. Another possibility is loss of hydrogen from imidazole that may be the site of protonation for a significant fraction of the ions. In the case of BK (nonapeptide) and gramicidin S (cyclic decapeptide), no loss or only minor $\mathrm{H}$ loss occurred and, hence, these charge-reduced peptides survived well past a $\mu \mathrm{s}$.

Minimized structures at the B3LYP/6-311 + $\mathrm{G}(2 \mathrm{~d}, \mathrm{p}) / / \mathrm{PM} 3$ level of theory [14] provide insight into these results. On average, more open or extended structures are favored for dipeptide dications (Figure 2a) because of the Coulomb repulsion between the two charged ends: the distance between the two nitrogens of the structure of $[\mathrm{GK}+2 \mathrm{H}]^{2+}$ shown in Figure 2a is 11.2 $\AA$, which gives a Coulomb repulsion energy of $1.3 \mathrm{eV}$ assuming an effective dielectric constant of one [15]. Thus, an energetic $\mathrm{H}$ radical generated by electron capture of any of the terminal ammonium can easily fly off leaving the backbone intact. In contrast, internal ionic $\mathrm{H}$-bonding and other $\mathrm{H}$-bonds play a role for triand larger peptides, e.g., $[\mathrm{GHK}+2 \mathrm{H}]^{2+}$ (Figure $2 \mathrm{~b}$ ). H-bonding may provide a "caging" effect where the translational energy of the "hot" $\mathrm{H}$ is dissipated into vibrational energy of the peptide reducing the fraction of $\mathrm{H}$ lost. Indeed Jeon et al. [10b] have shown that clustering with ammonia has a stabilizing effect on $\mathrm{NH}_{4}$ and $\mathrm{CH}_{3} \mathrm{NH}_{3}$ radicals and attributed this to hydrogen bonding. This interpretation is also in line with previous work on peptides, proteins [1a, 4a], and amino acid models, e.g., Breuker et al. [16] found that the chargereduced ion is the major product for large proteins. In contrast Tureček and coworkers [17] did not find intramolecular $\mathrm{H}$-bonding in hypervalent ammonium radicals increases the lifetimes of the radicals on a microsecond time scale.

The probability of formation of $c^{+}$and $z^{+\cdot}$ ions after electron capture is similar for di- and tripeptides, 0.15 to 0.35 (Table 1), despite the fact that internal ionic $\mathrm{H}$ bonding is significantly more feasible in tripeptides than in dipeptides. These results suggest that a direct interaction of the protonated site with heteroatoms in

Table 1. Probability $P$ of $z^{+\cdot}$ and $c^{+}$ion formation after electron capture to doubly-protonated peptides from sodium

\begin{tabular}{lcc}
\hline Peptide & No. of amino acids & $P$ \\
\hline \hline AK & 2 & $0.17(0.04)$ \\
GK & 2 & $0.20(0.05)$ \\
KK & 2 & $0.35(0.05)$ \\
AR & 2 & $0.15(0.04)$ \\
KWK & 3 & $0.18(0.05)$ \\
GHK & 3 & $0.16(0.04)$ \\
GGR & 3 & $0.19(0.05)$ \\
KYK & 3 & $0.22(0.05)$ \\
BK & 9 & $0.14(0.04)$ \\
AHF & 10 & $0.27(0.07)$ \\
SP & 11 & $0.19(0.05)$ \\
\hline
\end{tabular}

$\mathrm{BK}=$ bradykinin (RPPGFSPFR), SP = substance $\mathrm{P}$ (RPKPOQFFGLM), $\mathrm{AHF}=$ adrenocorticotropic hormone fragment 1-10 (SYSMQHFRWG). The probability $P$ is calculated as the total yield of $c^{+}$and $z^{+\cdot}$ ions divided by the total ionic yield of electron capture products. Uncertainties are given in the parentheses. 
the peptide backbone may not play an important role in the formation of $c^{+}$and $z^{+\cdot}$ ions. Larger peptides like BK and SP in which folding is even more important still display similar probabilities of 0.14 and $0.19( \pm 0.05)$, respectively, with the dominant product being the peptide monocation, $[\mathrm{M}+2 \mathrm{H}]^{+}$. A comparison between peptides of different size is complicated by the differing number of degrees of freedom. For a statistical process, larger peptides that have more degrees of freedom will dissociate more slowly for a given amount of energy that is deposited, thereby giving a lower fragmentation yield within the limited time scale for measurement. This would be especially important for any statistical processes that may lead to $\mathrm{N}-\mathrm{C}_{\alpha}$ bond breakage, but would not play a major role for nonstatistical pathways for cleavage of this same bond.

Spectra obtained from collisions between doublyprotonated bradykinin, $[\mathrm{BK}+2 \mathrm{H}]^{2+}$, and $\mathrm{Ne}$ and $\mathrm{Na}$ are shown in Figure 3. As was the case for SP, the relative yields of $c^{+}$ions in the difference spectrum for BK (Figure 4) are surprisingly similar to those obtained from ECD [18]. Still, the total production of $c^{+}$ions from the charge-reduced species is much less in ECID compared to ECD, indicating that some fraction of the $c^{+}$ and $z^{+\cdot}$ ions may be formed after a $\mu$ s (cf., second time scale of ECD), although differences in internal energy deposition with ECID versus ECD may account for differences in fragmentation extents. Future experiments using cesium that has lower ionization energy than sodium are planned to address this issue.

To test the importance of $\mathrm{H}$-bonding for the survival of a radical cation, ECID spectra of methanol-solvated peptides were obtained. The results for KWK, KYK, and AK with up to three methanol molecules attached (one for KWK and KYK and three for AK) are shown in Figure 5 in the region of the peptide monocation.
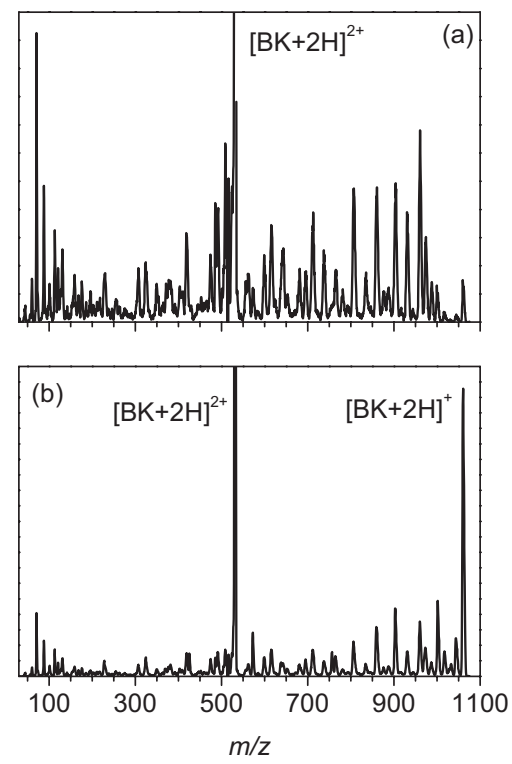

Figure 3. Product ion spectra obtained from the collisions between $[\mathrm{BK}+2 \mathrm{H}]^{2+}$ and (a) $\mathrm{Ne}$ and (b) Na.

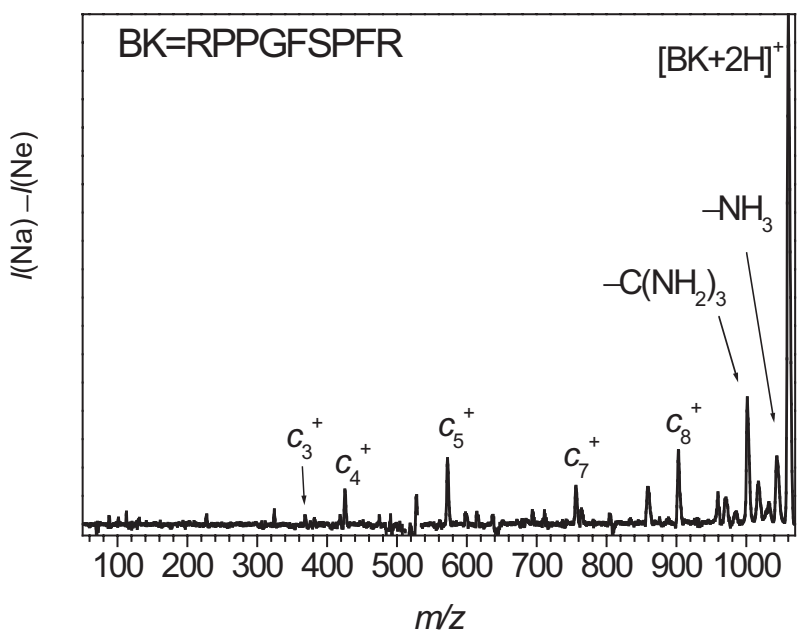

Figure 4. Differences between two spectra of bradykinin (cf., Figure 3); the spectrum was obtained by subtracting the spectrum with $\mathrm{Ne}$ from the one with $\mathrm{Na}$.

Solvation clearly increases the abundance of the tripeptide radical cation, and solvation of the dipeptide by three methanol molecules results in the survival of the intact radical cation for this species as well. Taken together with the previous findings, we conclude that hydrogen bonding is important to trap the $\mathrm{H}$ atom in the peptide and/or to act as a heat sink to dissipate the kinetic energy of the $\mathrm{H}$.

When just one methanol molecule is bound to [AK + $2 \mathrm{H}]^{2+}$, electron capture gives rise to rapid loss of the methanol as well as the $\mathrm{H}$ radical (Figure 6). Because the electron can potentially be captured at either of the ammonium sites, the observation of complete loss of methanol suggests that energy relaxation from the Rydberg state of the hypervalent ammonium radical must result in some conversion of the energy originating from electron transfer to vibrational excitation over the entire dipeptide. Loss of a methanol molecule can also be attributed to collisional activation that can occur in the ECID process. From the spectra of the dipeptide solvated with different number of methanol molecules, the survival of the intact radical cation after electron
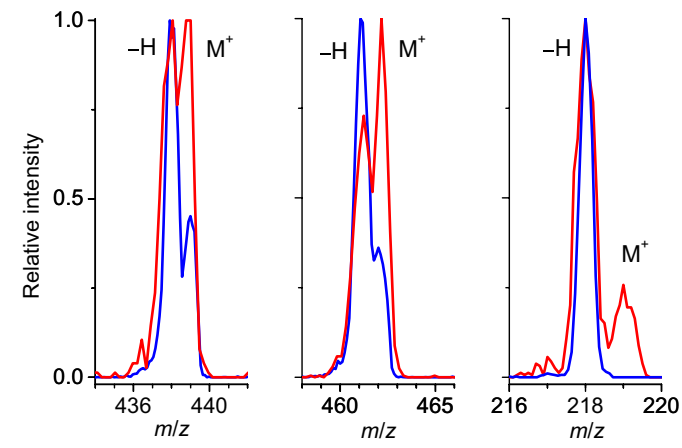

Figure 5. Partial ECID spectra of (a) $[\mathrm{KYK}+2 \mathrm{H}]^{2+}$ and $[\mathrm{KYK}+$ $2 \mathrm{H}]^{2+}\left(\mathrm{CH}_{3} \mathrm{OH}\right),(\mathbf{b})[\mathrm{KWK}+2 \mathrm{H}]^{2+}$ and $[\mathrm{KWK}+2 \mathrm{H}]^{2+}\left(\mathrm{CH}_{3} \mathrm{OH}\right)$, and (c) $[\mathrm{AK}+2 \mathrm{H}]^{2+}$ and $[\mathrm{AK}+2 \mathrm{H}]^{2+}\left(\mathrm{CH}_{3} \mathrm{OH}\right)_{3}$; bare ions are in blue, solvated ions are in red. 


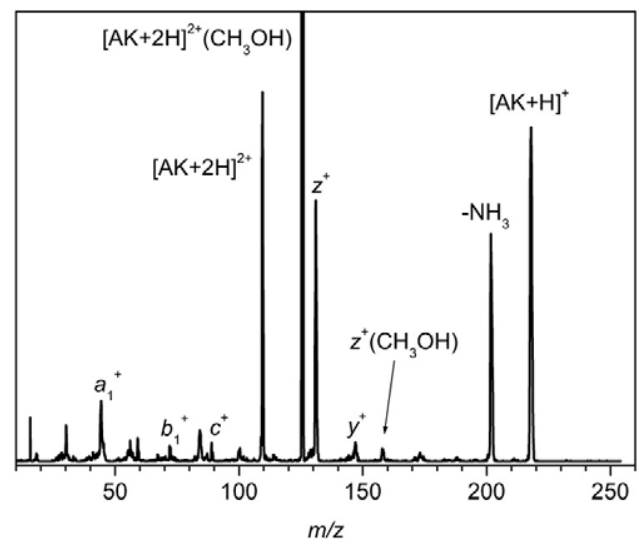

Figure 6. ECID spectrum of $[\mathrm{AK}+2 \mathrm{H}]^{2+}\left(\mathrm{CH}_{3} \mathrm{OH}\right)$.

capture requires cooling by evaporation of at least two methanol molecules. Indeed, the intensity of the [AK + $2 \mathrm{H}]^{+\cdot}$ peak relative to that of $[\mathrm{AK}+\mathrm{H}]^{+}$increases monotonically with the extent of solvation. For [AK + $2 \mathrm{H}]^{2+}\left(\mathrm{CH}_{3} \mathrm{OH}\right)_{6}$, the abundance of the completely desolvated $[\mathrm{AK}+2 \mathrm{H}]^{+\cdot}$ is nearly $50 \%$ that of $[\mathrm{AK}+\mathrm{H}]^{+}$ (Figure 7). In this ion, the methanol molecules are associated with the protonated sites and are most likely equally partitioned between these sites. Charge neutralization of either ammonium gives rise to evaporation of all methanol molecules ( $\sim$ three) attached to that site, and some or all are lost from the other site as well (Figure 7).

In the case of electron transfer to the tripeptide [GHK $+2 \mathrm{H}]^{2+}$ solvated by seven methanol molecules, [GHK $+2 \mathrm{H}]^{+}\left(\mathrm{CH}_{3} \mathrm{OH}\right)_{n}$ is more abundant than [GHK + $\mathrm{H}]^{+}\left(\mathrm{CH}_{3} \mathrm{OH}\right)_{n}$ for $n=0,1,2$, and 3, whereas $\mathrm{H}$ loss associated with methanol loss dominates for $n=4$ and 5 (Figure 8). The latter is surprising since the intact peptide radical cation was dominant after electron transfer to the bare dication (vide supra). Methanol solvation, however, weakens the internal ionic hydro-

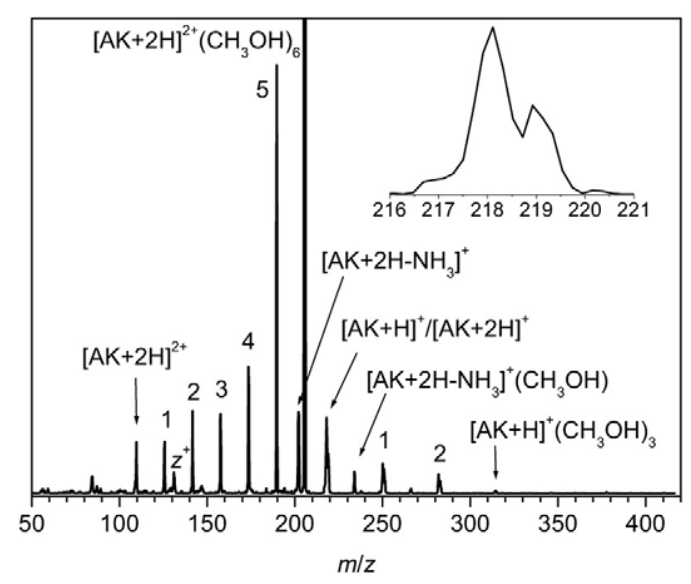

Figure 7. ECID spectrum of $[\mathrm{AK}+2 \mathrm{H}]^{2+}\left(\mathrm{CH}_{3} \mathrm{OH}\right)_{6}$. The inset shows the region around the $[\mathrm{AK}+\mathrm{H}]^{+}$and $[\mathrm{AK}+2 \mathrm{H}]^{+\cdot}$ peaks. The numbers refer to the number of methanol bound to the peptide ion, singly-or doubly-charged.

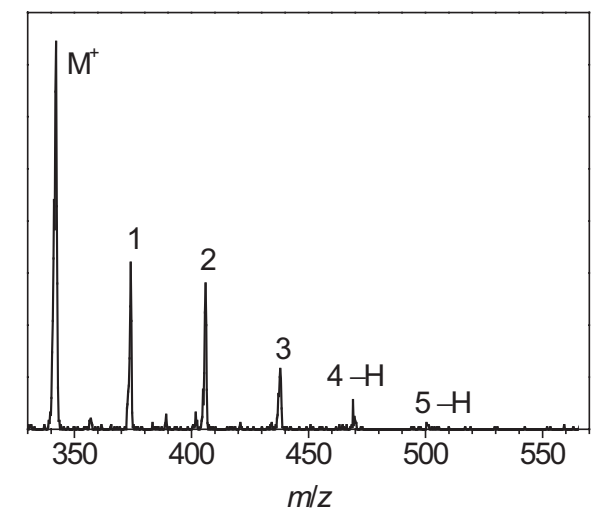

Figure 8. Partial ECID spectrum of $[\mathrm{GHK}+2 \mathrm{H}]^{2+}\left(\mathrm{CH}_{3} \mathrm{OH}\right)_{7}$ $\left(\mathrm{M}^{2+}=[\mathrm{GHK}+2 \mathrm{H}]^{2+}\right)$. The numbers, $n$, refer to the number of methanol bound to the singly-charged peptide. The peptide cation has lost a hydrogen for $n=4$ and 5 .

gen bonding between the ammonium and amide since the methanol molecules bind to the ammonium groups and the peptide is therefore less folded. This again reflects the strong importance of peptide folding for the loss of hydrogen.

In addition to effecting $\mathrm{H}$ loss, methanol solvation also changes the abundances of other fragments. The relative yield of $z^{+\cdot}$ ions after electron transfer to [AK + $2 \mathrm{H}]^{2+}, \quad[\mathrm{AK}+2 \mathrm{H}]^{2+}\left(\mathrm{CH}_{3} \mathrm{OH}\right)$, and $[\mathrm{AK}+$ $2 \mathrm{H}]^{2+}\left(\mathrm{CH}_{3} \mathrm{OH}\right)_{4}$ is $0.19,0.22$, and $0.09 \pm 0.01$, respectively. In contrast, the yield of $\mathrm{NH}_{3}$ loss is a factor of two higher for $[\mathrm{AK}+2 \mathrm{H}]^{2+}\left(\mathrm{CH}_{3} \mathrm{OH}\right)_{4}$ than that for $[\mathrm{AK}$ $+2 \mathrm{H}]^{2+}$ and $[\mathrm{AK}+2 \mathrm{H}]^{2+}\left(\mathrm{CH}_{3} \mathrm{OH}\right)$. Thus, solvation by methanol can either increase or decrease the propensity for survival of the intact cation, it increases loss of $\mathrm{NH}_{3}$, presumably at the site of electron capture, and reduces the formation of $c^{+}$and $z^{+\cdot}$ ions. The significantly lower yield of $c^{+}$and $z^{+\cdot}$ ions for the more highly solvated species could be due to the caging effect of methanol, which prevents the $\mathrm{H}$ from attaching onto the amide oxygen, or it could be due to an energy barrier for this process by providing a means by which energy can be rapidly removed, i.e., solvent evaporation.

\section{Conclusions}

In summary, ECID experiments on isolated and microsolvated di- and tripeptides show that ionic H-bonding tends to increase the yield of intact peptide radical cations. $\mathrm{H}$ loss from ammonium following electron capture is likely associated with a barrier but hydrogens originating from other sites than the ammonium radical also contribute to the total $\mathrm{H}$ loss signal. Tripeptides do not display a larger probability than dipeptides for undergoing $\mathrm{N}-\mathrm{C}_{\alpha}$ bond cleavage compared with dipeptides despite a larger propensity for internal ionic $\mathrm{H}$-bonding. Likewise, the probability of $\mathrm{H}$ loss from bare dipeptides and tripeptides is not directly correlated with the probability of $c^{+}$and $z^{+\cdot}$ ion formation. Solvent molecules around the protonation site can act as 
a cage as well as a heat sink, trapping the $\mathrm{H}$ atom and directing fragmentation. Finally, our data reveal that the predominant electron capture site is the ammonium groups with a probability of at least 70 to $80 \%$ (the yield of $\mathrm{H}$ and $\mathrm{NH}_{3}$ losses). It is still an open question what electronic state is populated, and we hope in the future to resolve this issue from experiments using cesium instead of sodium to unravel the importance of the energetics in the electron transfer process.

\section{Acknowledgments}

The authors acknowledge support from the vice-chancellor of UA for visiting professorships for TC and ERW. SBN gratefully acknowledges support from the Danish Natural Science Research Council (grant no. 21-04-0514) and Lundbeckfonden.

\section{References}

1. (a) Zubarev, R. A.; Kelleher, N. L.; McLafferty, F. W. Electron Capture Dissociation of Multiply Charged Protein Cations. A Nonergodic Process. J. Am. Chem. Soc. 1998, 120, 3265-3266; (b) Zubarev, R. A. Reactions of Polypeptide Ions with Electrons in the Gas Phase. Mass Spectrom. Rev. 2003, 22, 55-77; (c) Zubarev, R. A.; Haselmann, K. F.; Budnik, B.; Kjeldsen, F.; Jensen, F. Towards an Understanding of the Mechanism of Electron-Capture Dissociation: A Historical Perspective and Modern Ideas. Eur. J. Mass Spectrom. 2002, 8, 337-349; (d) Cooper, H. J.; Hakansson, K.; Marshall, A. G. The Role of Electron Capture Dissociation in Biomolecular Analysis. Mass Spectrom. Rev. 2005, 24, 201-222.

2. (a) Syka, J. E. P. Coon, J. J.; Schroeder, M. J.; Shabanowitz, J.; Hunt, D. F. Peptide and Protein Sequence Analysis by Electron Transfer Dissociation Mass Spectrometry. Proc. Natl. Acad. Sci. U.S.A. 2004, 101, 95289533; (b) Coon, J. J.; Ueberheide, B.; Syka, J. E. P.; Dryhurst, D. D.; Ausio, J.; Shabanowitz, J.; Hunt, D. F. Protein Identification Using Sequential Ion/Ion Reactions and Tandem Mass Spectrometry. Proc. Natl. Acad. Sci. U.S.A. 2005, 102, 9463-9468.

3. Hvelplund, P.; Liu, B.; Brøndsted Nielsen, S.; Tomita, S. Electron Capture Induced Dissociation of Peptide Dications. Int. J. Mass Spectrom. 2003, 225, 83-87.

4. (a) Zubarev, R. A.; Horn, D. M.; Fridriksson, E. K.; Kelleher, N. L.; Kruger, N. A.; Lewis, M. A.; Carpenter, B. K.; McLafferty, F. W. Electron Capture Dissociation for Structural Characterization of Multiply Charged Protein Cations. Anal. Chem. 2000, 72, 563-573; (b) Sze, S. K.; Ying, G.; Oh, H.; McLafferty, F. W. Top-Down Mass Spectrometry of a 29-kDa Protein for Characterization of Any Posttranslational Modification to Within One Residue. Proc. Natl. Acad. Sci. U.S.A. 2002, 99, 1774-1779.

5. (a) Syrstad, E. A.; Tureček, F. Toward a General Mechanism of Electron Capture Dissociation. J. Am. Soc. Mass Spectrom. 2005, 16, 208-224; (b) Tureček, F. N-C $\mathrm{C}_{\alpha}$ Bond Dissociation Energies and Kinetics in Amide and Peptide Radicals. Is the Dissociation a Nonergodic Process? J. Am. Chem. Soc. 2003, 125, 5954-5963; (c) Anusiewicz, I.; Berdys-Kochanska, J.; Simons, J. Electron Attachment Step in Electron Capture Dissociation (ECD) and Electron Transfer Dissociation (ETD). J. Phys. Chem. A 2005, 109, 5801-5813; (d) Sawicka, A.; Skurski, P.; Hudgins, R. R.; Simons, J.
Model Calculations Relevant to Disulfide Bond Cleavage Via Electron Capture Influenced by Positively Charged Groups. J. Phys. Chem. B 2003, 107, 13505-13511.

6. (a) Boltalina, O. V.; Hvelplund, P.; Jørgensen, T. J. D.; Larsen, M. C.; Larsson, M. O.; Sharoitchenko, D. A.; Sørensen, M. Electron Capture by Fluorinated Fullerene Anions in Collisions with Xe Atoms. Phys. Rev. A 2000, 62, 023202; (b) Larsson, M. O.; Hvelplund, P.; Larsen, M. C.; Shen, H.; Cederquist, H.; Schmidt, H. T. Electron Capture and Energy Loss is Similar to $100 \mathrm{keV}$ Collisions of Atomic and Molecular Ions on $\mathrm{C}_{60}$. Int J. Mass Spectrom. 1998, 177, 51-62.

7. Dookeran, N. N.; Yalcin, T.; Harrison, A. G. Fragmentation Reactions of Protonated $\alpha$-Amino Acids. J. Mass Spectrom. 1996, 31, 500-508.

8. Kulik, W.; Heerma, W. A Study of the Positive and Negative Ion Fast Atom Bombardment Mass Spectra of $\alpha$-Amino-Acids. Biomed. Environ. Mass Spectrom. 1988, 15, 419-427.

9. Tureček, F.; Syrstad, E. A. Mechanism and Energetics of Intramolecular Hydrogen Transfer in Amide and Peptide Radicals and Cation-Radicals. J. Am. Chem. Soc. 2003, 125, 3353-3369.

10. (a) Williams, B. W.; Porter, R. F. Energetics of Fragmentation of $\mathrm{CH}_{5}$, $\mathrm{H}_{3} \mathrm{O}$, and $\mathrm{NH}_{4}$ from Neutralized Ion-Beam Experiments. I. Chem. Phys. 1980, 73, 5598-5604; (b) Jeon, S.-J.; Raksit, A. B.; Gellene, G. I.; Porter, R. F. Formation of Hypervalent Ammoniated Radicals by Neutralized Ion-Beam Techniques. J. Am. Chem. Soc. 1985, 107, 4129-4133.

11. Nguyen, V. Q.; Sadilek, M.; Ferrier, J.; Frank, A. J.; Tureček, F. Metastable States of Dimethylammonium, $\left(\mathrm{CH}_{3}\right)_{2} \mathrm{NH}_{2}$. J. Phys. Chem. A 1997, 101, 3789-3799.

12. Yao, C.; Tureček, F. Hypervalent Ammonium Radicals. Competitive $\mathrm{N}-\mathrm{C}$ and $\mathrm{N}-\mathrm{H}$ Bond Dissociations in Methyl Ammonium and Ethyl Ammonium. Phys. Chem., Chem. Phys. 2005, 7, 912-920.

13. Leymarie, N.; Costello, C. E.; O'Connor, P. B. Electron Capture Dissociation Initiates a Free Radical Reaction Cascade. J. Am. Chem. Soc. 2003, $125,8949-8958$.

14. Frisch, M. J.; Trucks, G. W.; Schlegel, H. B.; Scuseria, G. E.; Robb, M. A.; Cheeseman, J. R.; Zakrzewski, V. G.; Montgomery, Jr., J. A.; Stratmann, R. E.; Burant, J. C.; Dapprich, S.; Millam, J. M.; Daniels, A. D.; Kudin, K. N.; Strain, M. C.; Farkas, O.; Tomasi, J.; Barone, V.; Cossi, M.; Cammi, R.; Mennucci, B.; Pomelli, C.; Adamo, C.; Clifford, S.; Ochterski, J.; Petersson, G. A.; Ayala, P. Y.; Cui, Q.; Morokuma, K.; Malick, D. K.; Rabuck, A. D.; Raghavachari, K.; Foresman, J. B.; Cioslowski, J.; Oritz, J. V.; Baboul, A. G.; Stefanov, B. B.; Liu, G.; Liashenko, A.; Piskorz, P.; Komaromi, I.; Gomperts, R.; Maritn, R. L.; Fox, D. J.; Keith, T.; Al-Laham, M. A.; Peng, C. Y.; Nanayakkara, A.; Challacombe, M.; Gill, P. M. W.; Johnson, B.; Chen, W.; Wong, M. W.; Andres, J. L.; Gonzalez, C.; Head-Gordon, M.; Replogle, E. S.; Pople, J.A. J. Gaussian 98, Revision A. 9; Gaussian Inc.: Pittsburgh PA, 1998.

15. Gross, D. S.; Rodriguez-Cruz, S. E.; Bock, S.; Williams, E. R. Measurement of Coulomb Energy and Dielectric Polarizability of Gas-Phase Diprotonated Diaminoalkanes. J. Phys. Chem. 1995, 99, 4034-4038.

16. Breuker, K.; Oh, H. B.; Cerda, B. A.; Horn, D. M.; McLafferty, F. W. Hydrogen Atom Loss in Electron-Capture Dissociation: A Fourier Transform-Ion Cyclotron Resonance Study with Single Isotopomeric Ubiquitin Ions. Eur. Mass. Spectrom. 2002, 8, 177-180.

17. (a) Shaffer, S. A.; Tureček, F. Hydrogen-Bonding in Transient Bifunctional Hypervalent Radicals by Neutralization-Reionization Mass-Spectrometry. J. Am. Soc. Mass Spectrom. 1995, 6, 1004-1018; (b) Shaffer, S. A.; Wolken, J. K.; Tureček, F. Neutralization-Reionization of Alkenylammonium Cations: An Experimental and ab Initio Study of Intramolecular N-H. . .C =C Interactions in Cations and Hypervalent Ammonium Radicals. J. Am. Soc. Mass Spectrom. 1997, 8, 1111-1123.

18. Polfer, N. C.; Haselmann, K. F.; Langridge-Smith, P. R. R.; Barran, P. E. Structural Investigation of Naturally Occurring Peptides by Electron Capture Dissociation and AMBER Force Field Modeling. Mol. Phys. 2005, 103, 1481-1489. 